\title{
SYNTHESIS AND CHARACTERIZATION OF CONDUCTING POLYMER NANOCOMPOSITES
}

\author{
Nitin Sugur ${ }^{1}$, Chandrashekhar Bendigeri ${ }^{2}$ \\ ${ }^{I}$ Student, Department of Mechanical Engineering, University Visvesvaraya College of Engineering, Bangalore, \\ Karnataka, India \\ ${ }^{2}$ Faculty, Department of Mechanical Engineering, University Visvesvaraya College of Engineering, Bangalore, \\ Karnataka, India
}

\begin{abstract}
Polymers have always been considered as insulators of electricity. No one would have believed 30 years ago that polymers could conduct as good as metals. Electrically conducting polymers combine the electrical properties of metals with the advantages of polymers such as light weight, greater workability, resistance to corrosion and chemical attack and the lower cost and have infiltrated our day to day life with a wide range of products, extending from most common consumer goods to highly specialized applications in space, aeronautics, electronics and nonlinear optics. The main aim of this project is to synthesize a polymer nanocomposite which has good mechanical strength as well as good electrical properties and to study the properties of the specimen with change in percentage of salt and nano-powder. Polyvinyl Pyrrolidone a water soluble polymer will be used as a base polymer material and potassium or ammonium iodide will be used as doping agent. Alumina, aluminum nitride \& nickel oxide $(<50 \mathrm{~nm})$ nano-powder will be used to increase mechanical strength and dielectric properties of the specimen.
\end{abstract}

Keywords: Synthesis, Polymer Nanocomposite, Polyvinyl Pyrrolidone, Potassium Iodide, Alumina

\section{INTRODUCTION}

Today the market is flooded with different materials. Modern life would be incomparably different without synthetic chemicals which are called as polymers. Manmade fibers are used in clothing, carpets and curtains while plastics are used in innumerable domestic and industrial applications and artificial joints paints and cleaning materials are all different forms of this important discovery. What is often forgotten is that at the beginning of 20th century the chemistry of large molecules was unknown and their synthesis was definitely unthinkable.

Polymers are generally produced as powders, pellets, and liquids. In order to produce polymeric products with desired shapes, thermoplastics must be melted and cool to a final product shape whereas thermosets must undergo further polymerization to complete cross linking reactions to finally solidify into the designed shape. These operations are called processing. Many factors influence the processing operations. Those include viscosity, orientation of heterogeneous phases, rate of reactions, and volatile formation. Among these factors, the viscosity consideration is by far the most dominant factors in processing. Viscosity is strongly influenced by temperature, share rate, molecular weight and its distribution, molecular structure of the polymeric chains and heterogeneity of materials. Thus, the study of flow behavior of polymeric materials, which is called rheology, is very important in understanding the proper conditions for processing.

A composite is a heterogeneous substance consisting of two or more materials which does not lose the characteristics of each component. This combination of materials brings about new desirable properties. Naturally occurring composites include tendon, bone, bamboo, rock, and many other biological and geological materials. For composite engineering applications, we restrict ourselves to synthetic polymer matrices which are used with naturally occurring mineral fillers such as silica, mica, and calcium carbonate, and synthetic fibers like glass fibers and carbon fibers.

Polymer nanocomposites (PNC) consist of a polymer or copolymer having nanoparticles or nanofillers dispersed in the polymer matrix. These may be of different shape (e.g., platelets, fibers, spheroids), but at least one dimension must be in the range of 1-50 nm. These PNC's belong to the category of multi-phase systems (MPS, viz. blends, composites, and foams) that consume nearly $95 \%$ of plastics production. These systems require controlled mixing/compounding, stabilization of the achieved dispersion, orientation of the dispersed phase, and the compounding strategies for all MPS, including PNC, are similar [1].

The transition from Micro to Nanoparticles lead to change in its physical as well as chemical properties. Two of the major factors in this are the increase in the ratio of the surface area to volume, and the size of the particle. The increase in surface area-to-volume ratio, which increases as the particles get smaller, leads to an increasing dominance of the behavior of atoms on the surface area of particle over that of those interior of the particle. This affects the properties of the particles when they are reacting with other particles. Because of the higher surface area of the nanoparticles, the interaction with the other particles within the mixture is more and this increases the strength, heat 
resistance, etc. and many factors do change for the mixture. An example of a Nano polymer is silicon Nano spheres which show quite different characteristics; their size is 40$100 \mathrm{~nm}$ and they are much harder than silicon, their hardness being between that of sapphire and diamond [2].

\section{SYNTHESIS OF POLYMER NANO COMPOSITE}

\subsection{Materials}

Polyvinyl Pyrrolidone (PVP) a water soluble polymer was selected as matrix material, potassium iodide/ammonium iodide was used as doping agent and Alumina nanopowder was selected as filler material.

PVP having density $1.2 \mathrm{~g} / \mathrm{cm}^{3}$ shows a number of interesting properties such as a high capability to interact with different kinds of molecules like iodine, detergents, drugs, dyes, aromatic compounds, carboxylic acids and many other compounds. Moreover, the biological behavior of PVP, or more specifically its physiological and pharmaceutical performance, is responsible of a variety of applications including its use as blood-plasma substitute or in hair sprays and other aerosol products. The chemical Structure of typical PVP is shown in Fig-1

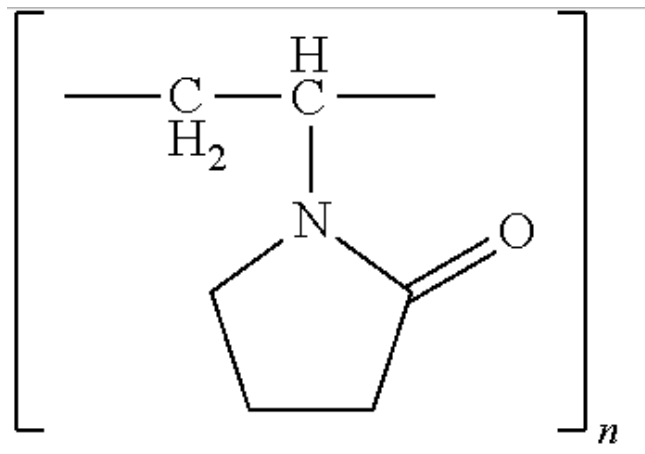

Fig -1: Chemical Structure of typical PVP

Aluminahaving density $3.95 \mathrm{~g} / \mathrm{cm}^{3}$ is insoluble in water most commonly occurring crystalline form, called corundum or $\alpha$-aluminium oxide, its hardness makes it suitable for use as an abrasive and as a component in cutting tools.Being fairly chemically inert and white, aluminia is a favored filler for plastics. Alumina is a common ingredient in sunscreen and is sometimes present in cosmetics such as blush, lipstick, and nail polish.

\subsection{Preparation of Polymer Nanocomposite}

Sample is prepared using Solution casting method using magnetic stirrer as shown in Fig 2. The inner surface of conical flask is cleaned with soft brush and cloth by using acetone. A silicon spray is applied on the cleaned surface.

After that $1 \mathrm{~g}$ weight of PVP and 10,20,30,40mg weight of Potassium/ammonium Iodide(KI/NH4I) using an $4 \mathrm{ml}$ water as a solvent is dissolved. The mixture of PVP with water is poured into a conical flask. The mixture is stirred in a magnetic stirrer at a speed of 500rpm with temperature of
$323 \mathrm{~K}$ by using a magnetic bellet for 15 minutes. After stirring, Potassium/ammonium Iodide is added to mixer stirred at a speed of 500rpm with temperature of $323 \mathrm{~K}$ by using a magnetic bellet for 30 minutes. After stirring, Nano powder and water mixed and poured into above conical flask and stirred at a speed of 500rpm for 15 minutes. The mixture of PVP, KI/NH4I, water, Nano powder is poured in petridish and the samples are allowed to solidify in open atmosphere as shown in Fig-3. The samples were cut into a proper size and the mechanical properties and structural behavior of the polymer composite specimen are tested.

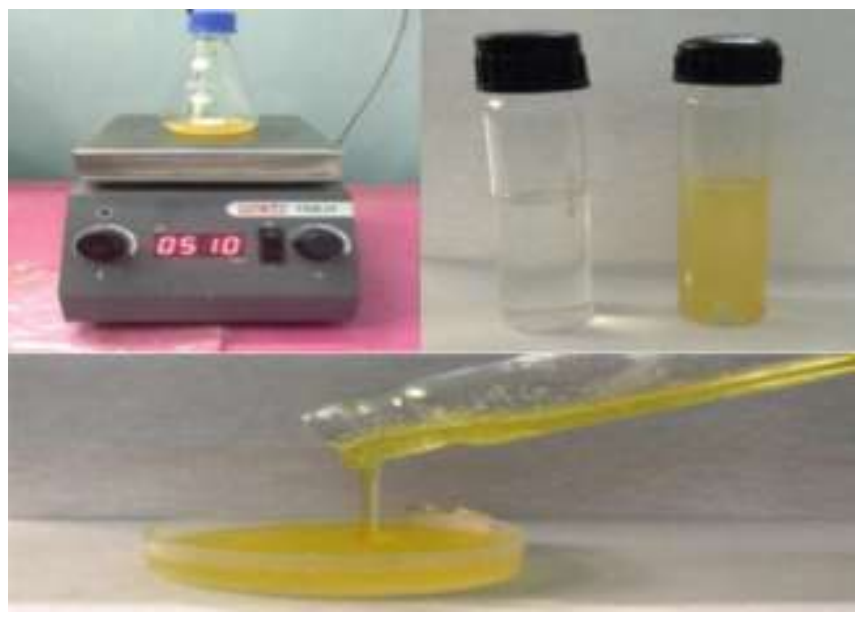

Fig -2: Solution casting method

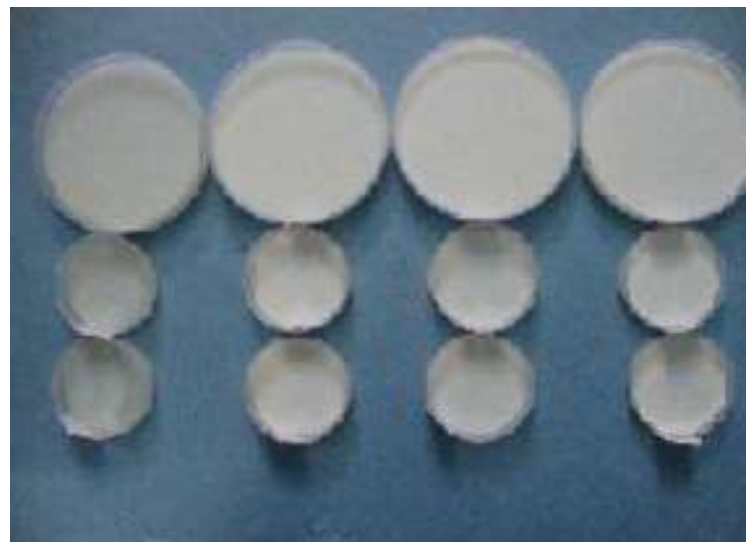

Fig -3: Sample preparation

\section{EXPERIMENTATION}

Characterization of polymer nano composites samples for microstructural study were conducted by SEM, FTIR and XRD; Electrical conductivity test was conducted by impedance spectroscopy and Mechanical test by nanoindentation.

\subsection{Impedance Spectroscopy}

Polymer composite doped with salt specimen was cut approximately into $20 \mathrm{~mm}$ diameter \& silver paste was applied uniformly over the specimen as shown in the figure 4 which act as electrode in the electrical conductivity test. 


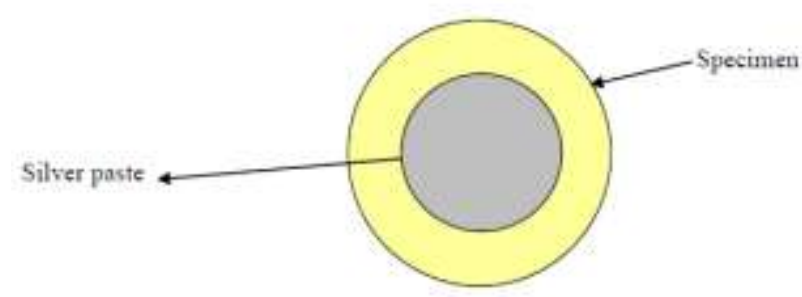

Fig -4: Specimen

Later the specimen was placed between the specimen holder by tightening screw which had point contact with specimen in Hioki LCR HiTester meter 3250 machine as shown in figure 5 at room temperature.

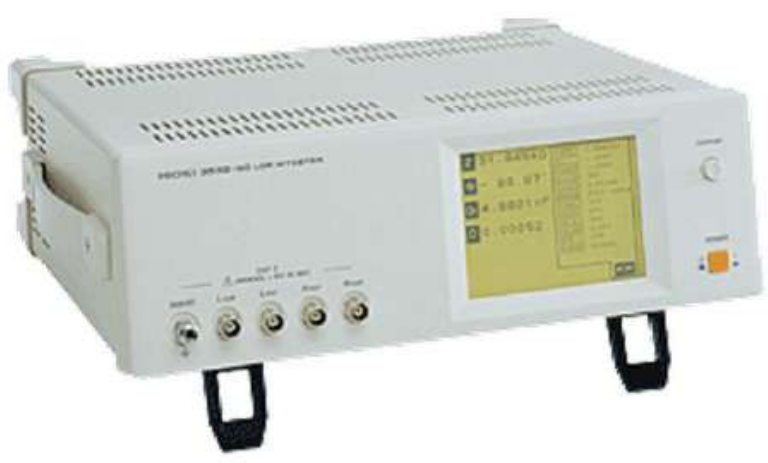

Fig -5: Hioki LCR HiTester meter 3250

Conductance values $\mathrm{G}$ at different range from $50 \mathrm{~Hz}-50$ $\mathrm{MHz}$ was measured using LCR meter for the specimen. Finally electrical conductivity for the specimen was measured using formula, $\sigma=\mathrm{Gt} / \mathrm{A}$ where $\mathrm{t}=$ thickness of specimen $=0.11 \mathrm{~cm}, A=$ Area of specimen $=\pi r^{2}=31.42 \mathrm{~cm}^{2}$

Electrical conductivity $\sigma$ was plotted versus logarithm of frequency range for $30 \% \mathrm{KI}$ to show the nature of graph for electrical conductivity of polymer with salt as shown in Graph-1.

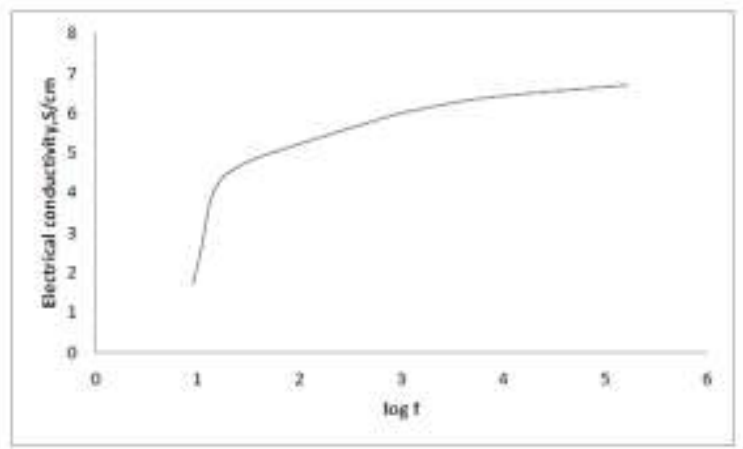

Graph -1: Electrical conductivity versus frequency

\subsection{X-ray Diffraction (XRD)}

PANalytical XRD machine as shown in fig 6 was used to perform XRD test. PVP, salts \& nano powders of approximately $2 \mathrm{~g}$ were placed in space provided for specimen holder and for nanocomposite specimen $1.5 \times 1 \mathrm{~cm}$ was cut \& placed in specimen holder.XRD was used to determine the microstructural behavior of Polymer nanocomposite.

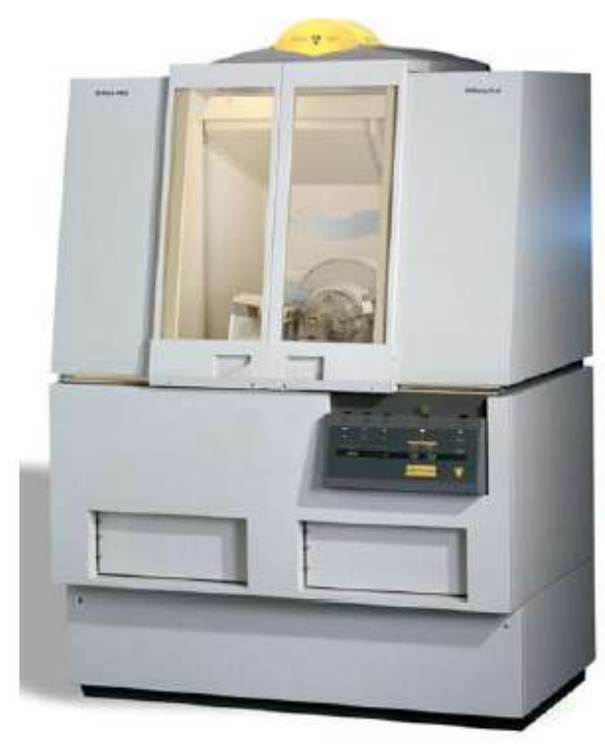

Fig -6: PANalytical XRD machine

Polymers are always amorphous but due to addition of crystalline nano powder there is introduction of crystallinity in polymer matrix. Degree of crystallinity is an important parameter for improving the conductivity (electrical and thermal) and mechanical property of the composites. Higher degree of crystallinity and more uniform crystalline structure of polymer matrix increase the possibility of conduction in the composites. Inorganicnanoparticles affect the crystallization behavior of PVP matrix and the influence of nanoparticles, on crystallinity of polymer was studied by using XRD. It is expected to fulfilling the two results with each other.XRD patterns of nanocomposite is as shown in Fig 7.

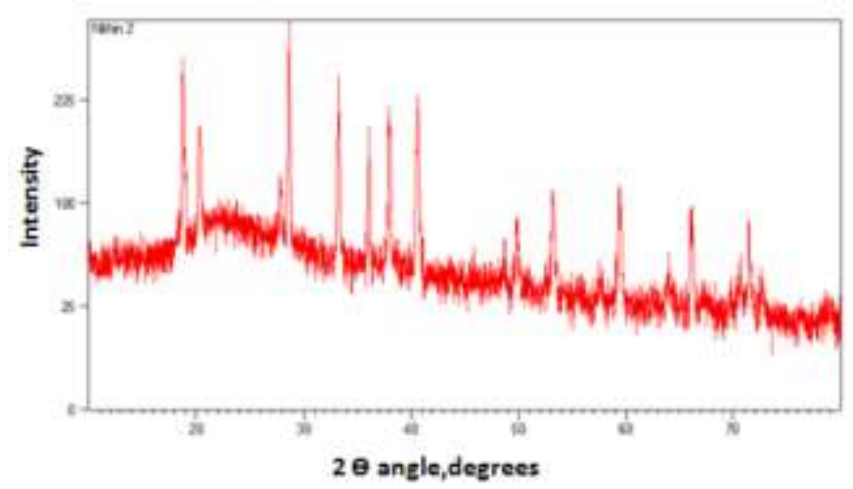

Fig -7: XRD pattern of nanocomposite

\subsection{Fourier Transform Infrared Spectroscopy (FTIR)}

Agile Technologies FTIR spectrometer 300 series was used to conduct FTIR test as shown in fig 8. This spectrometer simultaneously collects spectral data in a wide spectral range from 400 to $4000 \mathrm{~cm}-1$ range of wavelength. It was 
used to determine \% transmittance of intensity at various spectral range of wavelengths.

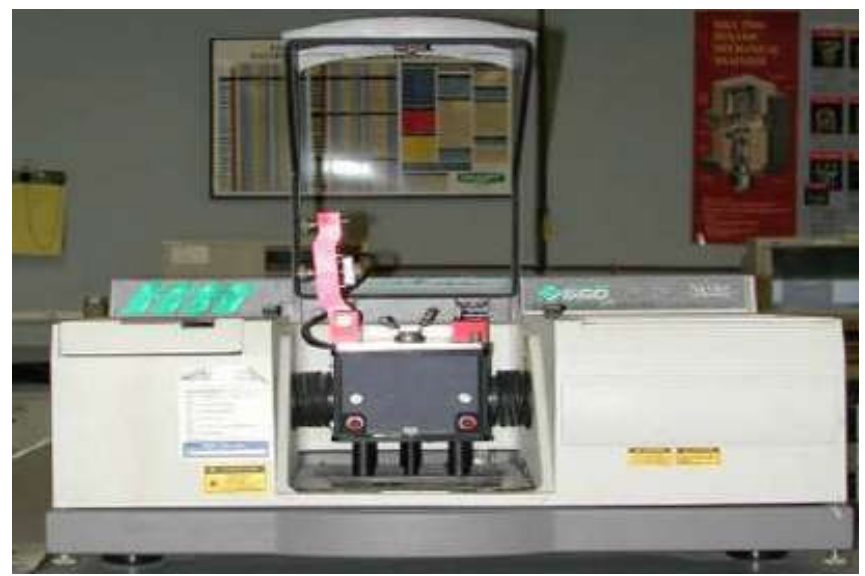

Fig -8: Agile Technologies FTIR spectrometer

Specimen was placed in the specimen holder and the \% transmittance was noted at different range of wavelength. This experiment was carried for five minutes for each specimen and the $\mathrm{x} y$ data was recorded in the computer

FTIR pattern for polymer nano compositeis as shown in fig 9. It can be observed that at there are steep fall in intensity which are the characteristics of polymer nanocomposites which are in agreement with the standard polymer nanocomposite characteristics.

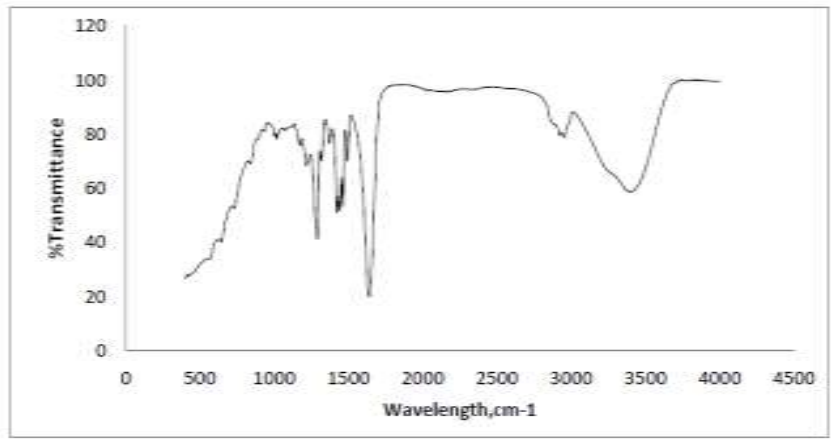

Fig -9: FTIR pattern for polymer nano composite

\subsection{Nanoindentation}

In nanoindentation small loads and tip sizes are used, so the indentation area may only be a few square micrometers or even nanometers. This presents problems in determining the hardness, as the contact area is not easily found. During the course of the instrumented indentation process, a record of the depth of penetration is made, and then the area of the indent is determined using the known geometry of the indentation tip. While indenting, various parameters such as load and depth of penetration can be measured. A record of these values can be plotted on a graph to create a loaddisplacement curve. These curves can be used to extract mechanical properties of the material.

Agile technologies G200 nanoindentor as shown in fig-10 was used to get the average modulus \& hardness for the polymer nanocomposite. Polymer nano composite specimen was cut approximately into $20 \mathrm{~mm}$ diameter and four specimens was placed in nano indentor specimen holder \& three times the test was conducted to get the average modulus \& hardness of polymer nanocomposite.

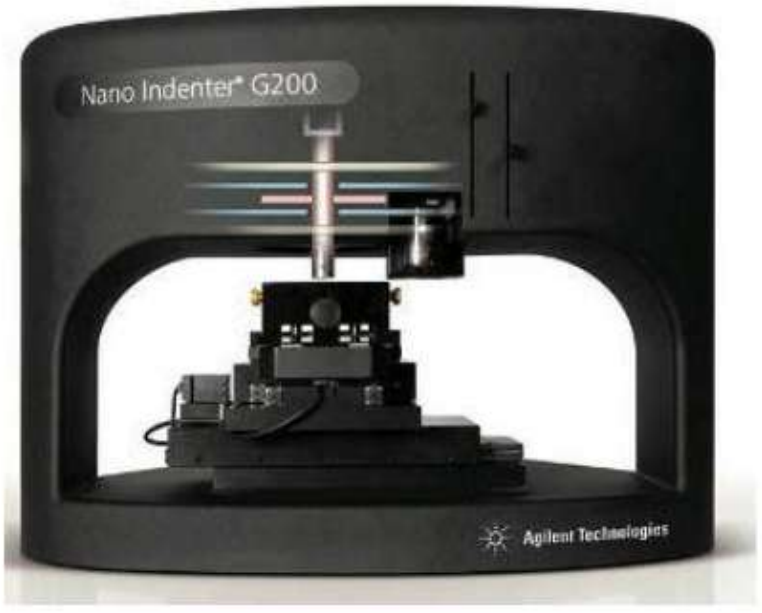

Fig -10: Agile technologies G200 nanoindentor

Nanoindentation test results of polymer nanocomposite were plotted as shown in graph-2 for Modulus, Hardness \& Load graphs versus displacement

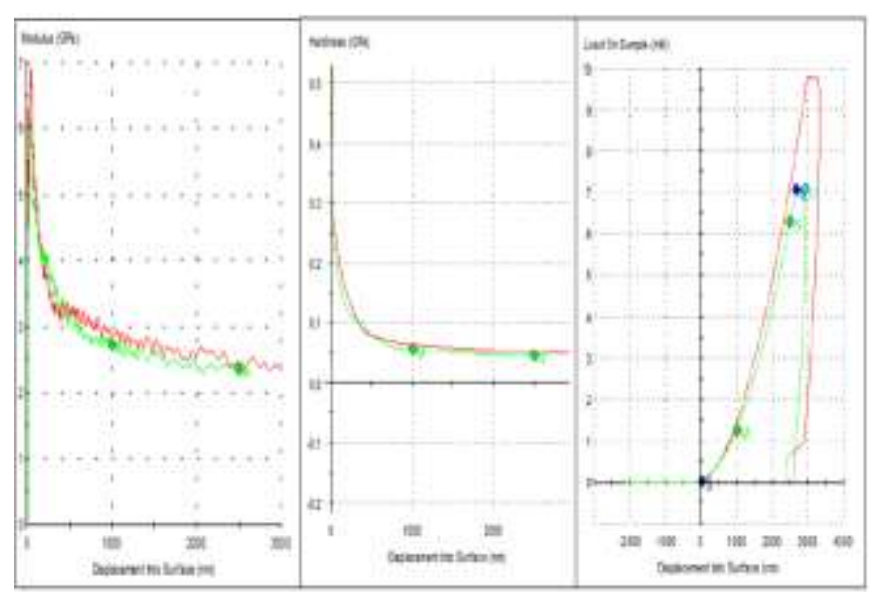

Graph 2: Nanoindentation plots

\subsection{Scanning Electron Microscope (SEM)}

SEM instrument JEOL JSM-6400lv as shown in figure 11 was used to characterize microstructures of the samples. SEM makes use of point to point scanning of the solid surface, which produces a clear image of specimens, and provides information about their size which lies in the range of micrometer. The sample was cut and placed on a SEM sample holder. Carbon tape was place under the sample and a small roll of carbon tape was placed against the sample to stabilize it on the sample holder. 


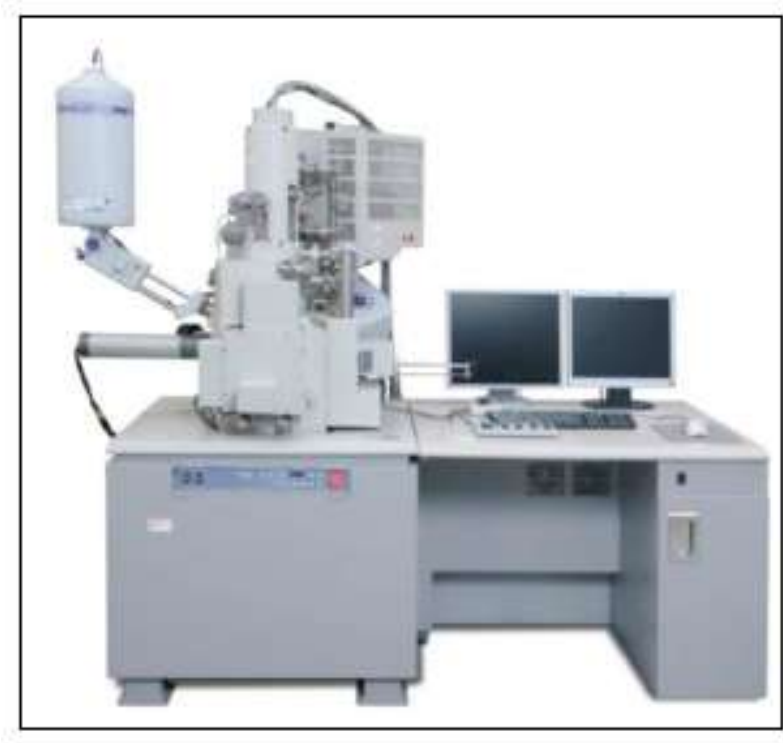

Fig -11: JEOL JSM-64001v SEM instrument

SEM images of polymer nanocomposite as shown in figure 12indicates distribution of nano powder in polymer composites which shows in white dots \& light black colored region showing salt in dark black colored polymer matrix.

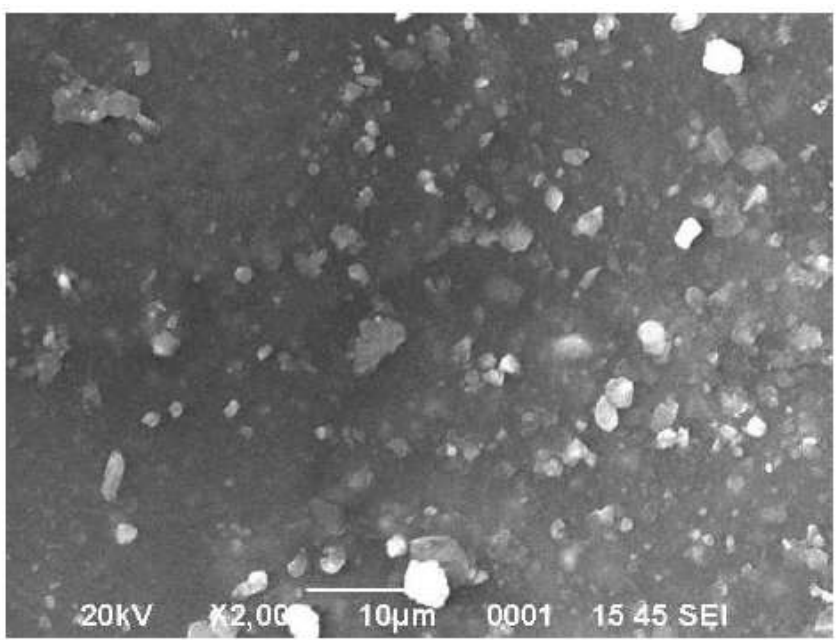

Fig -12: SEM image of polymer nanocomposite

\section{RESULTS AND DISCUSSIONS}

In this section the resultsobtained fromimpedance spectroscopy, XRD, FTIR, nanoindentation and SEM are tabulated or represented graphically to analyze behavior of Polymer nanocomposite.

\subsection{Impedance Spectroscopy}

Electrical conductivity for PVP+ 10, 20, $30 \& 40 \% \mathrm{KI}$ is tabulated as shown below table $1 \&$ graph is plotted as shown in Graph-3.
Table-1: Electrical conductivity of specimens

\begin{tabular}{|l|c|}
\hline Specimen & $\begin{array}{r}\text { Electrical Conductivity, } \sigma \\
\times 10^{-5} \mathrm{Scm}^{-1}\end{array}$ \\
\hline $\mathrm{PVP}+10 \% \mathrm{KI}$ & 0.154 \\
\hline $\mathrm{PVP}+20 \% \mathrm{KI}$ & 0.598 \\
\hline $\mathrm{PVP}+30 \% \mathrm{KI}$ & 3.4479 \\
\hline $\mathrm{PVP}+40 \% \mathrm{KI}$ & 1.818 \\
\hline
\end{tabular}

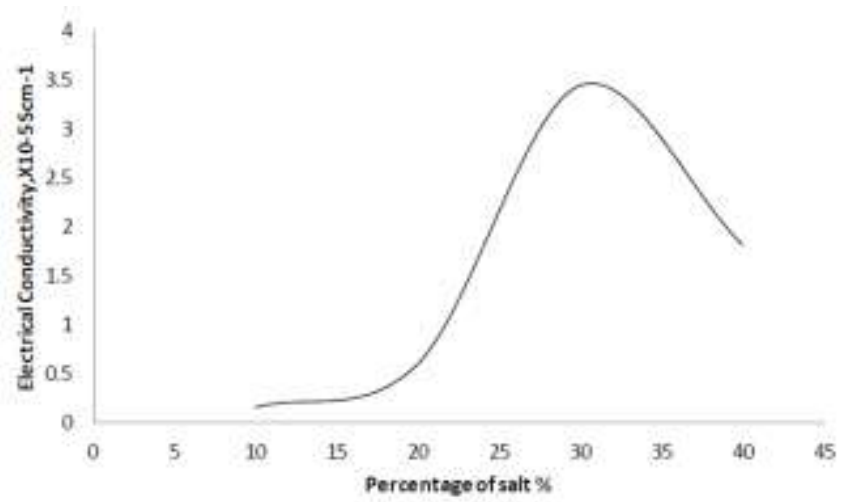

Graph-3: Electrical conductivity vs $\%$ of salt

It can be observed by the graph that electrical conductivity is maximum at $30 \%$ of salt so polymer nanocomposites were prepared with $30 \%$ salt \& addition of nanomaterial (A12O3, AlN and Ni2O3) at 4, 8, $12 \& 16 \%$.

Electrical conductivity for polymer nanocomposite was tabulated as shown below table 2

Table-2: Electrical conductivity of specimens

\begin{tabular}{|c|c|}
\hline Specimen & $\begin{array}{l}\text { Electrical Conductivity, } \sigma \\
\qquad \times 10^{-5} \mathrm{Scm}^{-1}\end{array}$ \\
\hline $\mathrm{PVP}+30 \% \mathrm{KI}+4 \% \mathrm{Al} 203$ & 1.2684 \\
\hline PVP $+30 \% \mathrm{KI}+8 \% \mathrm{Al} 203$ & 1.8879 \\
\hline PVP $+30 \% \mathrm{KI}+12 \% \mathrm{Al} 2 \mathrm{O} 3$ & 3.1446 \\
\hline PVP $+30 \% \mathrm{KI}+16 \% \mathrm{Al} 203$ & 2.6342 \\
\hline PVP $+30 \% \mathrm{KI}+4 \%$ AIN & 1,3661 \\
\hline PVP $+30 \% \mathrm{KI}+8 \%$ AIN & 3.1446 \\
\hline PVP $+30 \% \mathrm{KI}+12 \%$ AIN & 5.3301 \\
\hline PVP $+30 \% \mathrm{KI}+16 \%$ AIN & 4.8612 \\
\hline $\mathrm{PVP}+30 \% \mathrm{NH} 41+4 \% \mathrm{Ni} 2 \mathrm{O} 3$ & 1.2799 \\
\hline $\mathrm{PVP}+30 \% \mathrm{NH} 41+8 \% \mathrm{Ni} 2 \mathrm{O} 3$ & 2.559 \\
\hline $\mathrm{PVP}+30 \% \mathrm{NH} 41+12 \% \mathrm{Ni} 2 \mathrm{O} 3$ & 6.7303 \\
\hline $\mathrm{PVP}+30 \% \mathrm{NH} 41+16 \% \mathrm{Ni} 2 \mathrm{O} 3$ & 5.9722 \\
\hline
\end{tabular}

It can be depicted from the table 2 that polymer nanocompositeexhibits higher electrical conductivity at 12 $\%$ weight of nano material.

\subsection{X-ray Diffraction (XRD)}

For XRD patterns of nanocomposite as shown in Fig 8, the peaks are seen at the same $2 \Theta$ Angles where nanopowder show peak intensities. 


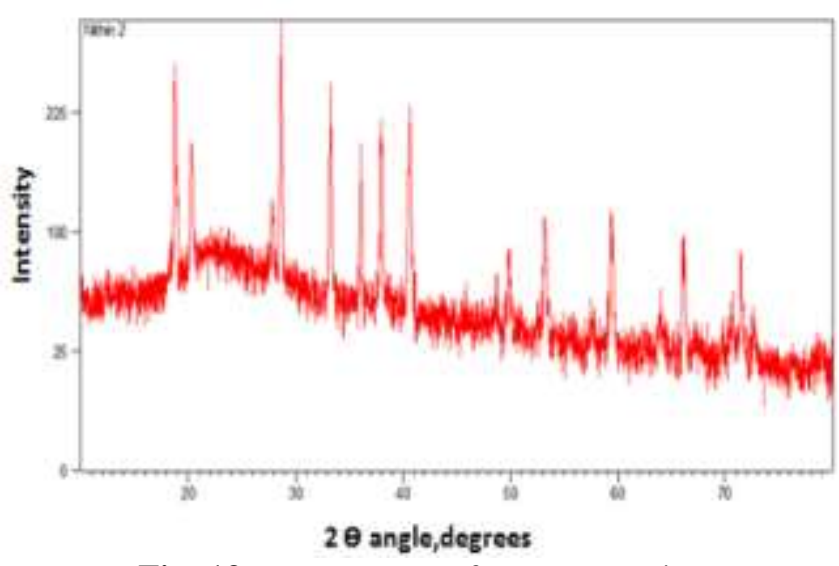

Fig -13: XRD pattern of nanocomposite

Inorganic nanoparticles affect the crystallization behavior of PVP matrix and the influence of nanoparticles, on crystallinity of polymer was studied by using XRD. It is expected to fulfilling the two results with each other.

The XRD patterns showed the presence of few crystalline peaks and amorphous humps indicating the semi crystalline nature of all the polymernanocomposites. It was clearly understood from the relative areas under these crystalline peaks that the polymer sample producedin plate form after solidification becomes highly crystalline.

\subsection{Fourier Transform Infrared Spectroscopy (FTIR)}

By observing the FTIR patterns it can be concluded that polymer nanocomposites shows the same intensity peak characteristics as shown by nanopowders. This shows that nanoparticles present in the polymer matrix which absorbs the light intensity at different wavelength and exhibits as polymer nanocomposites.

FTIR pattern for polymer nano compositeis as shown in fig 14. It can be observed that at there are steep fall in intensity which are the characteristics of polymer nanocomposites which are in agreement with the standard polymer nanocomposite characteristics.

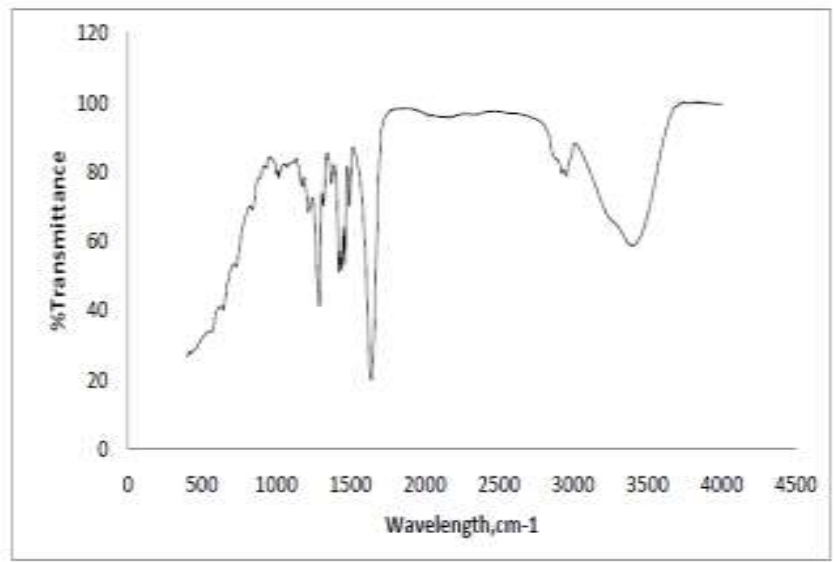

Fig -14: FTIR pattern for polymer nano composite

\subsection{Nanoindentation}

Nanoindentationresult for PVP+ 30\% KI+16\% Aluminais tabulated as shown below in table $3 \&$ graph is plotted as shown in Graph-4

Table-3: Nanoindentationresult for PVP+30\% KI

\begin{tabular}{|c|c|c|}
\hline Test \# & $\begin{array}{l}\text { Avg } \\
\text { Modulus } \\
{[1000-} \\
2500 \mathrm{~nm}] \\
\mathrm{GPa}\end{array}$ & $\begin{array}{l}\text { Avg } \\
\text { Hardness } \\
{[1000-} \\
2500 \mathrm{~nm}] \\
\mathrm{GPa}\end{array}$ \\
\hline 1 & 2.7 & 0.06 \\
\hline 2 & 2.5 & 0.05 \\
\hline Mean & 2.6 & 0.05 \\
\hline
\end{tabular}

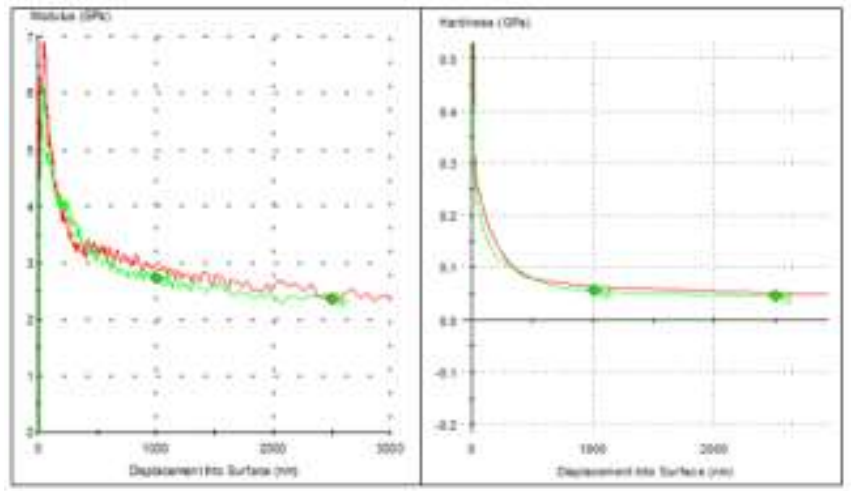

Graph-4: Nanoindentation results

Graph-4 shows how the modulus of the specimen varies with the displacement into surface of specimen and hardness of specimen varies with displacement into surface.

It can be observed that for both hardness \& modulus graphs for displacement range 1000-2000nm the values becomes constant \& the nanoindentor takes the value \& record in the computer.

By taking the slopes of this graph modulus is calculated and hardness is calculated by maximum load, Pmax, divided by the residual indentation area Ar.

\subsection{Scanning Electron Microscope (SEM)}

SEM images of polymer nanocomposite isas shown in figure 15 . It indicates distribution of nano powder in polymer composites which shows in white dots \& light black colored region showing salt in dark black colored polymer matrix. 


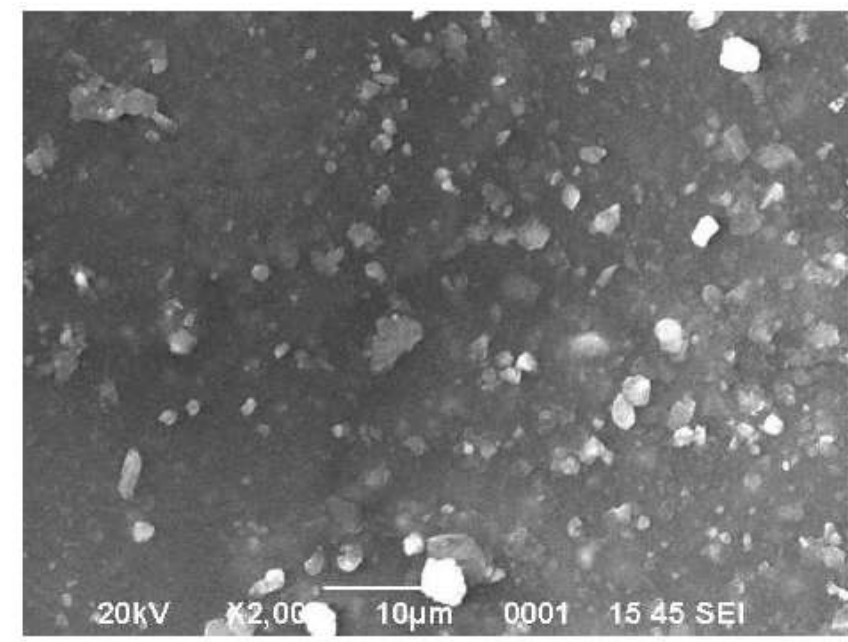

Fig -15: SEM image of polymer nanocomposite

By analyzing the SEM distribution of salt in samples were verified. The higher porosity revealed the improved ionic migration in the sample. SEM image of Nano composite reveled presence of distinct spherulites in the sample.

\section{CONCLUSION}

- Impedance Spectroscopy study implied that with increase in frequency electrical conductivity increases to a certain level $\&$ then comes to a saturation up to a certain frequency.

- X-ray diffraction (XRD) studies implied the higher degree of amorphous nature of the polymer electrolytes by reducing the intensity of characteristic peaks. XRD patterns of PVP polymer nanocomposites doped Nano powders showed the decrease of intensity of peaks corresponding to pure Nano powder with the increase of Nano powder wt $\%$ ratio suggesting a decrease in the crystallinity of the complex.

- SEM is used to investigate the morphology of the samples. By analyzing the SEM images, Distribution of salt in samples were verified, the higher porosity revealed the improved ionic migration in the sample. SEM image of Nano composite reveled presence of distinct spherulites in the sample.

- $\quad$ FTIR is used to investigate the spectral distribution of the nanoparticles. By analyzing the FTIR images, distribution of nanoparticles in samples were verified, the lower $\%$ transmittance depicted the characteristics of nanocomposite.

- Nano indentation shows the displacement into surface (in $\mathrm{nm}$ ) decreases for polymer nanocomposite which implies improved mechanical properties such as Hardness \& Modulus of elasticity when compared to polymer doped with salt.

\section{REFERENCES}

[1]. Melt-processed blends of zein with polyvinylpyrrolidone, David J. Sessaa,, Kristen K. Woodsa, Abdellatif A. Mohameda, Debra E. Palmquistb Plant Polymer Research, National Center for Agricultural
Utilization Research, USDA-ARS, Peoria, IL 61604, USA Applied Chemistry International Conference 2011.

[2]. ElectrospunPolyvinylpyrrolidone-PMMA Nanoparticle Composite Nanofibers P. Kongjumnean, P. Sunintaboon and T. VongsetskulPACCON2011 (Pure and Applied Chemistry International Conference 2011).

[3]. Thermal and FTIR study of polyvinylpyrolidone/lignin blends M.F.Silva, C.A.da Silva, F.C. Fogo journal of thermal analysis and calorimetry, Vol,79 (2005)367 -370.

[4]. Preparation of polyvinylpyrrolidone-protected Prussian blue nanocomposites in microemulsionZhonghao $\mathrm{Li}$, Jianling Zhang, Tiancheng Mu, Jimin Du, Zhimin Liu, Buxing Han, Jing Chen Nanotechnology conference 2010.

[5]. Synthesis and Characterization of a Gel-Type Electrolyte with Ionic Liquid Added for Dye-Sensitized Solar Cells -Yan Shi Tien-Li Chen,2 Chih-Hao Chen,3, 4 and Kun-Ching Cho.

[6]. Solutions Containing $\mathrm{NaCl}$ : Electrochemical and Thermodynamic Study, LaylaA,Waffa,kMekhamer.int,j, electrochem, sci, 7 (2012) 8578-8596.

[7]. Synthesis of Nano Crystalline MgAl2O4 Spinel Powder by Microwave Assisted Combustion Leila Torkian, Mostafa M Amini, ZohrehBahrami Vol. 26 No. 5.

[8]. The crystallization and physical properties of Al-doped ZnO nanoparticles K.J. Chen a, T.H. Fang b, F.Y. Hung c, L.W. Ji b, S.J. Chang a, S.J. Young a, Y.J. Hsiao Applied Surface Science 254 (2008) 5791-5795.

[9]. Tien-Li Chen,2 Chih-Hao Chen "Investigation on electrical and dielectric properties of PVP:KCLO4 polymer electrolyte films", "American Journal of Pure \& Applied Physics", Vol. 51, May 2013, pp. 362-366.

[10]. L. Ferna'ndez, G. Arranz, L. Palacio, C. Soria , M. Sa'nchez, G. Pe'rez, A. E. Lozano. A. Herna'ndez, P. Pra'danos "Functionalization of alpa-alumina cores by polyvinylpirrolidone: properties of the resulting biocompatible nanoparticles in aqueous suspension", "Springer Science+Business Media" volume J Nanopart Res (2009) 11, pp341-354.

[11]. Jianling Zhang, Tiancheng $\mathrm{Mu}$ "Structural and Optical Properties of Li+: PVP \& Ag+: PVP Polymer Films" "scientific research, Materials Sciences and Applications",Volume 2011, 2,PP 1688-1696.

[12]. Z. Naemi , M. Jafar-Tafreshia, M. Fazlib, "Studies on Properties of Ag\Al2O3 Nanocomposite Synthesized by Solution Combustion Technique Under Novel Condition", "Journal of nanostrcture", Volume JNS 2 (2012) pp 183189.

[13].. C. Soria , M. Sa'nchez, G. Pe'rez "Lithium ion conducting solid polymer blend electrolyte based on biodegradable polymers", Vol. 36, No. 2, April 2013, pp. $333-$ 339.

[14]. A.I.Y. Tok , F.Y.C. Boey, X.L Zhao "Novel synthesis of $\mathrm{Al} 2 \mathrm{O} 3$ nano-particles by flame spray pyrolysis", "Elsevier Journal of Materials Processing Technology" Volume 178 (2006) pp 270-273

[15]. L. Palacio, C. Soria "Ion Transport and Discharge Characteristics of Polymer Blend (PVP/PVA) Electrolyte Films Doped with Potassium Iodide" "AIP Conference Proceedings;12/1/2010” Vol. 1313 Issue 1, p168. 


\section{BIOGRAPHIES}

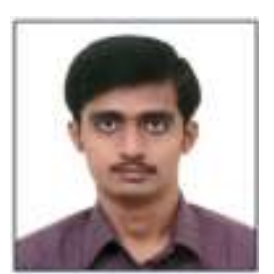

Mr. Nitin Sugur received his B.E degree in Mechanical Engineering from VTU, India (2005), presently doing his M.E degree in advanced materials \& technology at UVCE, Bangalore University, India. Presently his project is based on the field of Polymer Nanocomposite. His research interests include Composites, NanoTechnology and Nanomaterials

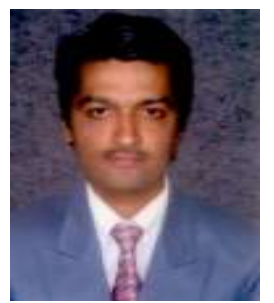

Dr. Chandrasekhar Bendigeri presently working as AssociateProfessor in UVCE, Bangalore university India. He obtained his B.E degree in Mechanical engineering from Bangalore University, India and ME in Machine Design from UVCE, Bangalore University. $\mathrm{He}$ obtained his Ph.D. in the field of Nanotechnology from Bangalore University. He has guided more than $20 \mathrm{ME}$ students and currently guiding 5 research scholars. His field of interests include Composites, NanoTechnology and Nanomaterialsstress analysis etc. 